\title{
O texto queiroziano e seu percurso crítico
}

Laile Ribeiro de Abreu

Doutoranda em Literatura Brasileira do Programa de Pós-Graduação em Estudos Literários / UFMG

\begin{abstract}
RESUMO
Este ensaio procura apresentar, parcialmente, a crítica disponível sobre Rachel de Queiroz desde o primeiro romance, O quinze (1930), até Memorial de Maria Moura (1992), enfatizando a crítica sobre o último romance de forma mais aprofundada.
\end{abstract}

Palavras-Chave

Rachel de Queiroz, Literatura Brasileira, romances, crítica

\section{INTRODUÇÃO}

A obra ficcional de Rachel é composta por seis romances, a saber: O quinze (1930), João Miguel (1932), Caminho de pedras (1937), As três Marias (1939), Dôra, Doralina (1975) e Memorial de Maria Moura (1992). Em todos eles, a mulher é representada como personagem que traz em seu âmago um desejo latente de liberdade, quase nunca alcançado devido à submissão que lhe é imposta por uma sociedade patriarcal.

O ensaísta Eduardo de Assis Duarte vê a obra e a vida de Rachel de Queiroz como uma "espécie de marco ou emblema do processo de emancipação social da mulher brasileira no século XX”. Mostra, ainda, que a inovação do texto da autora dá-se pelo ponto de vista da mulher, o que imprime nos textos um "duplo desrecalque, pois neles falam tanto a classe, quanto o gênero oprimido". ${ }^{1}$

Já em O quinze (1930), a personagem Conceição destoa do pensamento feminino da época, por se interessar pela política e por uma literatura mais contestadora e, principalmente, por ter aversão ao casamento, o que, para a época, era uma postura inovadora. A busca

\footnotetext{
${ }^{1}$ DUARTE. Classe e gênero nos romance de Rachel de Queiroz, p. 105.
} 
feminina pela liberdade prossegue gradativamente nas personagens dos outros romances, culminando em Maria Moura, última personagem construída pela ficção queiroziana, caracterizada por Maria Lúcia Dias Leite Barbosa ${ }^{2}$ como a personagem que coroa as demais, por reunir em si os caracteres das antecessoras com um agravante: é mulher que conquista sua liberdade plena, realizando a busca irrealizável pelas personagens dos outros romances: Conceição, Santa, Noemi, Guta e Dôra.

Entretanto, há um traço comum a todas as protagonistas: o fracasso quanto à sexualidade. Nenhuma das mulheres da ficção queiroziana se realiza plenamente no amor, nem mesmo Maria Moura. Nos romances, resolve-se a questão amorosa pelo desaparecimento da pessoa amada, que foge ou morre, deixando a personagem feminina marcada para sempre, mas conservando-se a tradição. Essas obras, também, carregam em si o fatalismo e a ausência de um final feliz. A busca da liberdade pelas letras ou pelas armas impõe às personagens queirozianas a solidão. A liberdade de autodeterminar-se pede o sacrifício da constituição da família e da maternidade.

A tradição é trabalhada por Rachel por meio da construção de narrativas que revisitam a cultura nordestina - o homem nordestino e, principalmente, a mulher nordestina. Os textos permitem a revisão do que passou, a relembrança, o trabalho de Penélope nos rastros deixados pelos antepassados, estabelecendo-se a aproximação entre o passado e o presente e assegurando-se que "através da tradição, algo é dito e o dito é entregue de geração a geração". ${ }^{3}$

A memória é substrato de boa parte dos romances e crônicas produzidas pela autora cearense, em mais de 75 anos de produção literária, prestigiada pela crítica e por reedições e traduções de suas obras em várias partes do mundo. Nos anos 1960, Rachel trabalhava intensamente na produção de crônicas para diversos jornais no Brasil inteiro ${ }^{4}$ e mantinha, semanalmente, a crônica para a "Última Página”, seção da revista O Cruzeiro. Essa parceria perdurou de 1945 a 1975, ano do encerramento da revista. Essa época caracterizou-se também por uma efervescência acadêmica e foi um momento especial para a consolidação da crítica literária no Brasil. Rachel era pouco conhecida no meio acadêmico como ficcionista, pois seu

\footnotetext{
${ }^{2}$ BARBOSA. Protagonistas de Rachel de Queiroz: caminhos e descaminhos.

${ }^{3}$ BORNHEIM. Tradição contradição, p. 15.

${ }^{4}$ A saber: O Ceará, Diário de Notícias, O Jornal, O Estado de S. Paulo, Diário de Pernambuco, O Povo, Correio da Manhã, Diário da Tarde, O Estadão, Última Hora, Jornal do Comércio, entre outros.
} 
nome era associado às crônicas, e estas compunham um gênero que não era bem explorado pela crítica, por ser considerado um gênero menor, “ao rés-do-chão”. 5

Heloísa Buarque de Hollanda $^{6}$ ainda ressalta a questão política como sendo motivadora para o sombreamento da obra de Rachel por parte da crítica acadêmica. Rachel tinha parentes militares e, em sua casa no Rio de Janeiro, recebia a visita de alguns deles. Por isso, sua residência foi considerada ponto de conspiração. O certo é que recusa, em 1961, o convite do presidente Jânio Quadros para ocupar o cargo de Ministra da Educação, justificando-se: "Sou jornalista e gostaria de continuar sendo apenas jornalista."7 Mas aceita a nomeação, em 1966, pelo presidente Humberto de Alencar Castelo Branco, um daqueles militares aparentados, para ser delegada do Brasil na 21 a Sessão da Assembleia Geral da Organização das Nações Unidas, na Comissão dos Direitos do Homem, demonstrando a sua pouca vontade de envolver-se em cargos públicos de chefia, mas, ao mesmo tempo, evidenciando o seu engajamento nas questões que discutissem a liberdade e a igualdade humana, tema recorrente em toda a sua obra.

A autora Nelly Novaes Coelho vê a presença de Rachel nas letras brasileiras como “emblemática”, afirmando que "sua verve de cronista se consagra a partir de sua presença, durante os anos de 1940 a 1970, na última página da revista O Cruzeiro, tornando-se um dos nomes mais conhecidos e queridos da crônica jornalística brasileira”. 8 Em relação aos romances, a autora discorre sobre uma gradual mudança de "planos de consciência de livro para livro”, afirmando que Memorial de Maria Moura chega ao plano existencial-mítico.

Depois de ter publicado Dôra, Doralina, Rachel foi escolhida para ocupar a cadeira $\mathrm{n}^{\circ}$ 5 na Academia Brasileira de Letras (ABL), no dia 4 de agosto de 1977, tomando posse no dia 4 de novembro do mesmo ano. Foi a primeira mulher a assumir esse papel de destaque junto a outros imortais. ${ }^{9}$ Em julho de 2003, poucos meses antes do falecimento de Rachel, o escritor José Luís Lira lança uma biografia editada pela Academia Brasileira de Letras intitulada No alpendre com Rachel. O autor é, segundo a crítica, um dos poucos neste país que pode discorrer em profundidade sobre a vida e a obra da escritora cearense.

\footnotetext{
${ }^{5}$ CANDIDO. A vida ao rés-do-chão.

${ }^{6}$ HOLLANDA. O éthos Rachel, p. 103-115.

${ }^{7}$ INSTITUTO MOREIRA SALLES. Cadernos de Literatura Brasileira: Rachel de Queiroz, p. 24.

${ }^{8}$ COELHO. Dicionário crítico de escritoras brasileiras, p. 551.

${ }^{9}$ Uma curiosidade é o fato de Rachel ter falecido, em 2003, no mesmo dia e mês de sua posse na ABL.
} 


\section{DE O QUINZE A DÔRA, DORALINA}

É com o pseudônimo de “Rita de Queluz” que Rachel de Queiroz assina seus primeiros textos, enviados para o jornal O Ceará em meados de 1927. Nenhum desses textos recebeu edição, porque a própria autora viria a explicar, posteriormente, que "não mereciam, eram muito ruins". 10

Rachel recorre à memória daqueles que viveram a seca de 1915 para construir o nome de seu livro de estreia, O quinze, lançado em agosto de 1930, em edição do Estabelecimento Graphico Urânia, financiada pela família. No romance, a escritora recorda o sofrimento ainda latente na memória nordestina daquele ano terrível, embora ela mesma não guarde consigo essas memórias. Vale-se, então, da memória social da região associada à experiência própria de mulher agreste e acostumada ao que, posteriormente, João Cabral de Melo Neto chamaria de "vida severina".

Em Fortaleza, o livro não encontrou tanto sucesso, entretanto, ao ser lançado no Rio de Janeiro, recebeu elogios de Augusto Frederico Schmidt. Graciliano Ramos, ao conhecer $O$ quinze, duvidou da autoria feminina que se inscrevia em sua capa. Posteriormente, o autor recorda-se do equívoco e comenta:

O quinze caiu de repente ali por meados de 30 e fez nos espíritos estragos maiores que o livro de José Américo, por ser de mulher e, o que na verdade causava assombro, de mulher nova. Seria realmente de mulher? Não acreditei. Lido o volume e visto o retrato no jornal, balancei a cabeça: não há ninguém com este nome... pilhéria. Uma garota fazer romance! Deve ser pseudônimo de sujeito barbado. ${ }^{11}$

Esse estranhamento de Graciliano Ramos, amigo pessoal de Rachel, justifica-se pelo fato de que não era nada comum, naquela época, uma escrita feminina voltada para questões tão ácidas e que trouxessem uma economia de linguagem, que resultava numa escrita sóbria, vigorosa e, segundo Heloísa Buarque de Hollanda, “antibarroca, avessa a qualquer demagogia no moderno romance nordestino”. ${ }^{12}$

O escritor e crítico Davi Arrigucci Jr. afirma que $O$ quinze surpreende pela autoria feminina, pelo gênero e por estar enraizado na tradição literária nordestina, "marcada pela experiência, pelo modo de ser e pela tradição oral da vida cearense”. ${ }^{13}$ O livro traz como

\footnotetext{
${ }^{10}$ QUEIROZ. Rachel de Queiroz, p. 32.

${ }^{11}$ RAMOS. Linhas tortas, p. 29.

${ }^{12}$ HOLLANDA. O ethos Rachel, p. 103.

${ }^{13}$ ARRIGUCCI JR. O sertão em surdina, p. 88.
} 
novidade o que ele chama de “virada da perspectiva literária”, pois converte a personagem feminina em sujeito da narrativa e não em objeto. O crítico destaca Conceição, personagem leitora que se contrapõe à sequidão do ambiente em que vive e, "no sentido latente entre essa interioridade e o sertão, [revela-se] o desacordo entre uma alma e o mundo - eixo que ordena a construção do romance”. ${ }^{14}$ A linguagem, próxima da oralidade, vem simples e livre. A narração é feita em terceira pessoa, chegando ao discurso indireto livre, "próximo ao monólogo interior - as mesmas armas de que disporá Graciliano Ramos, para contar por dentro a experiência de seus retirantes quase sem palavras, resumidos às suas Vidas secas”. ${ }^{15}$

Toda a ficção criada por Rachel de Queiroz seguirá essa linha escritural diferenciada, sempre se ocupando em retratar a vida sofrida do povo nordestino, especialmente da mulher nordestina. João Miguel (1932), segundo romance da autora, é o único que traz no título um personagem masculino. Entretanto, não é ele que surpreende o leitor, mas Santa, esposa de João Miguel, a qual desconstrói a imagem da mulher padrão, uma vez que age por seus instintos sexuais e não os reprime. Para garantir a publicação desse romance, Rachel rompe com o Partido Comunista, pois a obra não passa pelo crivo da cúpula do partido, que acha inadmissível que um operário tire a vida de outro operário e propõe à Rachel que altere essa e outras questões. ${ }^{16}$

A autora não concorda com a censura ao texto. Prefere romper com o partido e editar a obra, segundo ela, "sem tirar nenhuma vírgula”. ${ }^{17}$ Essa postura evidencia a autonomia intelectual e a liberdade de criação da escritora. Ao prefaciar a $7^{a}$ edição da obra, Tristão de Athayde afirma que João Miguel é um aprimoramento de $O$ quinze e que, nesse texto, a obra se desprende do seu criador:

É precisamente o que se verifica no João Miguel em face de $O$ quinze. Neste, é a autora que aparece acima do tema e do estilo. Já naquele, a autora como que desaparece. Quem vive agora é João Miguel, é Salu, é a prisão. (...) são os personagens, é o ambiente, é a obra. ${ }^{18}$

Em Caminhos de pedras, terceiro romance editado em 1937, Rachel de Queiroz trabalha a questão política de maneira direta, abandonando a temática da seca, distanciando-se da paisagem nordestina. Trata-se de um romance sobre a organização partidária no Ceará e

\footnotetext{
${ }^{14}$ ARRIGUCCI JR. O sertão em surdina, p. 91.

${ }^{15}$ ARRIGUCCI JR. O sertão em surdina, p. 95.

${ }^{16}$ QUEIROZ. As três Rachéis (entrevista), p. 27.

${ }^{17}$ QUEIROZ. As três Rachéis (entrevista), p. 27 et seq.

${ }^{18}$ QUEIROZ. João Miguel, p. 3.
} 
suas engrenagens autoritárias e, com ele, a escritora reposiciona-se diante do Partido Comunista. O título do livro, associado a seu enredo, não parece uma escolha aleatória. Embora se desvie do flagelo da seca, permanece com sua raiz nordestina voltada para as questões sociais e tem como questão fundamental a discussão do papel da mulher na sociedade em que se insere. Heloísa Buarque de Hollanda destaca que a trilogia representada por O quinze, João Miguel e Caminho de pedras legitima “a habilidade no desenho, desafia invariavelmente a lógica patriarcal desta primeira metade do século XX”. ${ }^{19}$

Em As três Marias, a escritora adota o foco narrativo em primeira pessoa, o que se repetirá nos demais romances. O espaço ficcional da obra corresponde a um colégio interno onde três amigas, Maria da Glória, Maria José e Maria Augusta - a Guta - conhecem-se e, cada qual à sua maneira, vivem as dificuldades sociais impostas a elas pela condição de mulher. O crítico Adonias Filho destaca que “(...) as personagens femininas, a partir do encontro no colégio de freiras, em seus destinos próprios - as três Marias -, permitiram a escavação interior, favorecendo a sondagem social na apreensão da sociedade burguesa provinciana.”20 Mário de Andrade tece comentários elogiosos ao romance, destacando a beleza "límpida" de sua linguagem. ${ }^{21}$

Essa obra inspirou uma novela no horário das dezoito horas, na Rede Globo de Televisão, em 1980. Dois dos romances queirozianos ganharam adaptações para a televisão. Memorial de Maria Moura foi adaptado para minissérie em 1994. As versões televisivas das obras não substituem, no entanto, a leitura dos livros. Elzira Divina Perpétua afirma que o livro permite a volta sistemática ao texto sempre que o leitor julgar necessário, tornando o contato com a obra mais efetivo e indispensável. ${ }^{22}$

Os críticos consideram o intervalo de 36 anos entre a publicação de As três Marias (1939) e Dôra, Doralina (1975) como um hiato na obra de Rachel de Queiroz, e alguns comparam esse intervalo com o que ocorreu entre a publicação de Sagarana (1946) e Grande sertão: veredas (1956). Nesse período, porém, Rachel se dedica à publicação de crônicas e duas peças teatrais. A edição de Dôra, Doralina representa, simbolicamente, a retomada de sua carreira como romancista e, a despeito do hiato na produção romanesca da escritora, pode-se supor um diálogo entre as crônicas publicadas nesse período e os romances, pois há

\footnotetext{
${ }^{19}$ HOLLANDA. O éthos Rachel, p. 104.

${ }^{20}$ ADONIAS FILHO. O romance brasileiro de 30, p. 88.

${ }^{21}$ ANDRADE. O empalhador de passarinho.

${ }^{22}$ PERPÉTUA, Elzira Divina [Rachel de Queiroz].
} 
elementos comuns entre eles. Há alguma menção sobre esse aspecto em críticas acadêmicas relativas à pesquisa genética dos textos de Rachel.

Por ocasião do lançamento de Dôra, Doralina, o crítico Lausimar Lans escreve um artigo para o suplemento literário do jornal Minas Gerais, evidenciando a importância do estilo racheliano para a compreensão do homem nordestino e o resgate da cidade do Rio de Janeiro. Nessa direção, segundo ele, “a escritora nos dá plena consciência dos cenários de sua terra nordestina e da fascinação de um Rio de Janeiro que vai longe”, ${ }^{23}$

Em Dôra, Doralina, a autora retoma o cenário nordestino que inspirou suas primeiras criações e que nunca abandonou, não só nos romances como também nas crônicas, estabelecendo o sertão como seu ponto de partida e de chegada. No entanto, o Rio de Janeiro, especialmente a Ilha do Governador, onde residiu por vários anos, também é cenário recorrente de diversas crônicas ${ }^{24}$ e do romance $O$ galo de ouro, publicado em 40 edições da revista O Cruzeiro, em 1950, e organizado em livro apenas em 1985. Para o crítico Wilson Martins, o resultado da junção dos dois cenários “(...) foi o soberbo Dôra, Doralina que, segundo parece, desnorteou a crítica e não foi reconhecido em sua justa medida como livro que se vinha juntar a uma nova idade do romance brasileiro". ${ }^{25}$

Jerri Antônio Langaro discorre sobre a postura oligárquica de Maria Moura e Maria das Dores (Dôra), protagonistas dos romances Dôra, Doralina e Memorial de Maria Moura. A primeira personagem é forçada a abandonar seu posto de sinhazinha ao transmigrar-se para o posto de chefe de uma cabroeira que lhe obedece sem restrições; a segunda, depois da morte do marido e de acirradas as divergências com a mãe, decide aventura-se acompanhando um grupo de teatro mambembe encontrando um novo amor - o Comandante -, o qual fará com que Dôra assuma o mais tradicional dos papéis femininos, o de dona de casa. Após a morte de Senhora e, posteriormente, do Comandante, Dôra retorna à fazenda Soledade para assumir sua herança e, de certa forma, encarnar a postura oligárquica de sua mãe, Senhora, perpetuando o continuísmo patriarcal.

Em Dôra, Doralina, a trama se desenrola nos anos 1930 e tem o sertão nordestino e o Rio de Janeiro como ambientes. Em Memorial de Maria Moura, a obra é ambientada no sertão, mas não há como afirmar precisamente que se trata do sertão nordestino. Essa questão sobre espaço/tempo esclarece para o leitor o continuísmo da ideologia patriarcal, visto que as

\footnotetext{
${ }^{23}$ LANS. A fenomenologia da comunicação em Rachel de Queiroz, p. 11.

24 São cerca de 3.000 crônicas, de acordo com a pesquisa feita. Disponível em: $<$ http://puc.riodigital.com.puc-rio.br>. Acesso em: 9 jan. 2010.

${ }^{25}$ MARTINS. Rachel de Queiroz em perspectiva, p. 69.
} 
três personagens, Maria Moura, Dôra e Senhora, reproduzem o modelo masculino nas relações de poder.

\section{A CRÍTICA SOBRE O MEMORIAL DE MARIA MOURA}

Memorial de Maria Moura foi aclamado pela crítica e um dos mais explorados pela crítica acadêmica em dissertações e teses. Editado em 1992 pela Siciliano, recebeu prêmios importantes, como o prestigioso e internacional "Prêmio Camões" e o "Prêmio Juca Pato", ambos em 1993. O romance foi traduzido para o francês, em 1995, por Cécile Tricoire (Éditions Métailié).

Passados 18 anos da edição de seu penúltimo romance, Rachel revigora a temática feminina tendo as paisagens nordestinas como cenário, embora não exista no texto uma definição precisa do ambiente que circunda as ações. O livro não traz uma paisagem agreste, seca como em $O$ quinze, mas mantém aquela mesma sobriedade de linguagem. As menções são feitas a lugares localizados em todo o Nordeste e no Centro-Oeste. Em conversa com a estudiosa Maria de Lourdes Dias Leite Barbosa, Rachel afirma que o Limoeiro e a Serra dos Padres, dois espaços centrais na narrativa, localizam-se na região Centro-Oeste. ${ }^{26}$

O escritor e crítico Antônio Houaiss declara que Memorial de Maria Moura é um texto que honraria a história da literatura brasileira. Entre outras considerações, ele ainda destaca a "mestria no domínio do vocabulário e da sintaxe" em consonância com "uma mestria psicológica que engrandece a natureza da criação”. Houaiss classifica como “arqueologia verbal” o trabalho de Rachel no que tange à exploração da linguagem regional, devido ao reduzido número de vocábulos regionalistas que dispõe para o manejo do texto, afirmando que

(...) é aí que o milagre [do] escritor se manifesta forte: Rachel consegue adequar cada situação mental de cada personagem a essa legitimação verbal arqueológica, dando, paralelamente, um viço quase inaugural não só às expressões dialogais diretas, senão que, sobretudo, às mentadas nas passagens dos discursos indiretos aparentes. ${ }^{27}$

Francisco Carvalho ${ }^{28}$ chama a atenção para dois pontos interessantes trabalhados no último romance: a tradição resgatada pela autora para a construção de Maria Moura e a opção narrativa para o texto. O romance revisita personagens emblemáticas da ficção nordestina

\footnotetext{
${ }^{26}$ BARBOSA. Protagonistas de Rachel de Queiroz: caminhos e descaminhos, p.74.

${ }^{27}$ HOUAISS. Memorial de Maria Moura, p. 4-6.

${ }^{28}$ CARVALHO. Textos e contextos, p. 94-96.
} 
como Luzia-Homem, de Domingos Olímpio (1903), e $D^{a}$ Guidinha do Poço, romance de Manuel de Oliveira Paiva editado em 1952 por Lúcia Miguel Pereira, sessenta anos após a morte do autor. A personagem Luzia fora inspirada na história de Maria Francisca de Paula Lessa, latifundiária que teve um caso de justiça em Quixeramobim em 1853.

Essas personagens, além de outras da Literatura Brasileira, como Diadorim, de João Guimarães Rosa, possivelmente contribuíram para a formação de Maria Moura. No que tange à narrativa, Francisco Carvalho classifica como "engenhosa” a técnica usada pela romancista, pois enriquece "os conteúdos [narrados] com novas situações e novas possibilidades, dá mais dinamismo e colorido ao romance e, ao mesmo tempo, impede que o curso da história seja conduzido exclusivamente pela onisciência da principal narradora” ${ }^{29}$ Exceção feita à Santinha, Maria Bonita e Nazaré, são as personagens femininas que arregimentam a narrativa. Mesmo que Memorial de Maria Moura traga mais de uma voz narrativa, inclusive vozes masculinas entremeadas, é a voz feminina, especialmente a de Maria Moura, que se sobrepõe numa espécie de liderança imposta. Trata-se, afinal, de seu Memorial.

Mônica Raissa Schpun ${ }^{30}$ compara a Rainha Elisabeth I da Inglaterra (1533-1603), uma das três personalidades a quem Rachel dedica a obra, a Maria Moura. A Rainha, assim como Moura, não se casou. Era órfã de mãe, teve que lutar e se impor para ter seus direitos de herdeira assegurados, vencendo seus inimigos e marcando seu reinado com um grande avanço econômico. Outra interseção entre a Rainha e a chefe de jagunço eram as preferências amorosas, pois ambas tiveram seus favoritos. No caso da Rainha, nunca se soube o motivo que a levou a escolher favoritos e não um rei. Quanto a Moura, essa questão é bem simples: a presença de um esposo lhe tiraria bens e, principalmente, poder; ela tinha uma visão bem lúcida sobre isso e não perderia o poder de mando por nada, nem por um grande amor. Essa determinação da personagem explica sua opção por trasvestir-se com as roupas herdadas do pai, bem como seu cinturão, pois ela vê nessa mudança a resolução de seus problemas e o encontro de sua liberdade.

Por retratar exatamente a realidade da época, a personagem Maria Moura segue a mesma linha das matriarcas que não assumiam uma relação amorosa, mas viviam-na clandestinamente, sempre com alguém cuja força e poder fossem inferiores aos delas. Maria Moura só não conta com o imprevisto de se apaixonar por Cirino, um homem que contraria as escolhas próprias das matriarcas. Maria Moura era "Lampião de saias (...) apenas com o

\footnotetext{
${ }^{29}$ CARVALHO. Textos e contextos, p. 94.

${ }^{30}$ SCHPUN. Lé com lé, cré com cré? Fronteiras móveis e imutáveis em Memorial de Maria Moura.
} 
complicador da sua ambiguidade masculino-feminino que vem à tona quando ela se apaixona pelo homem que a trai e que um dia terá de matar”. 31 A escritora Maria Osana de Medeiros Costa apresenta $^{32}$ três pontos instigantes do último romance de Rachel: as vozes discursivas, o confronto masculino/feminino, representado por Maria Moura e Beato Romano, e a morte como símbolo de libertação e redenção.

Ângela Harumi Tamaru ${ }^{33}$ faz uma análise comparativa entre as personagens Maria Moura e Beata Maria do Egito, que dá nome a uma peça teatral queiroziana publicada em 1958. Ambas, segundo Tamaru, agregam entre si múltiplas influências que as tornam transgressoras da ordem patriarcal ou das virtudes cristãs. Maria Moura aproxima-se da donzela-guerreira pelas vestimentas masculinas e o cabelo cortado, colocando-se na defesa dos perseguidos pela Justiça, praticando roubos e, quando necessário, assassinatos. Torna-se matriarca pelo poder, pela riqueza e pela força, que a fazem conhecida e (des)temida. Maria do Egito desconstrói a imagem de Beata pura ao entregar seu corpo como instrumento de resignação e luta pelo Juazeiro de Padre Cícero, evocando uma matriz hagiográfica, a de Santa Maria Egipcíaca, que lembra as hierodulas, cortesãs sagradas do mundo antigo. Sempre que preciso, Tamaru retoma as protagonistas que antecederam Maria Moura, na ficção, como matrizes para a concepção das personagens estudadas e D. Guidinha do Poço, de Manuel de Oliveira Paiva. Ela parte da protagonista de $O$ quinze, Conceição, a primeira que não se casou e não se rendeu à subserviência de uma sociedade retrógrada, decidida a se entregar mais às leituras que a um par amoroso incompatível. Fora da ficção, são revisitadas figuras históricas, como a Rainha Elisabeth I, familiares de Rachel de Queiroz, como Dona Rachel e Dona Bárbara de Alencar e outras matriarcas, como Dona Federalina de Lavras e Marica Macedo.

Walnice Aparecida Matos Vilalva ${ }^{34}$ analisa a manutenção da donzela-guerreira europeia até a atualidade como uma espécie de herança do processo de colonização. O romance brasileiro, ao explorar essa donzela, insere-se em um novo espaço, o sertão. Vilalva escolhe, como obras para serem analisadas, Grande sertão: veredas e Memorial de Maria Moura, porque acredita que essas obras permitam uma reelaboração da performance e o aprofundamento de elementos configurais. Antônio Carlos de Miranda Pacheco ${ }^{35}$ apresenta

\footnotetext{
${ }^{31}$ CHIAPPINI. Literatura e cultura no Brasil: identidades e fronteiras, p. 69.

${ }^{32}$ COSTA. Maria Moura, uma saga de poder, amor e morte.

${ }^{33}$ TAMARU. A construção literária da mulher nordestina em Rachel de Queiroz.

${ }^{34}$ VILALVA. Marias: estudo sobre a donzela-guerreira no romance brasileiro.

${ }^{35}$ PACHECO. Personagens em construção no Memorial de Maria Moura: estudo da gênese do Beato Romano.
} 
um estudo dos manuscritos literários que acompanharam Rachel de Queiroz na elaboração da obra Memorial de Maria Moura, destacando a construção do personagem Padre José Maria, o Beato Romano. Como metodologia, o autor utiliza-se das teorias da Crítica Genética, analisando os mais de 2.000 fólios que compõem os documentos de produção da obra, além da agenda da autora e outros documentos nomeados na tese Documentos avulsos.

Ana Maria Camargo Figueiredo ${ }^{36}$ procura apreender como os conceitos e as imagens do sertão e do jagunço, na televisão, apresentaram o regionalismo e, também, como se revelaram como forma particular de resgate da brasilidade sucumbida pela globalização, que tornou a todos cidadãos do mundo. A escolha das obras deu-se por terem marcado um tempo na televisão brasileira (décadas de 1980 e 1990). O trabalho de produção ficcional da televisão revisita as origens da ficção, valendo-se dos gêneros épico e dramático, fazendo o telespectador participar de uma história de heróis com homens e mulheres representantes de um passado cruel e violento. Para a autora, esses aspectos consolidaram o formato minissérie “como um campo do experimento, do lírico e da memória”. ${ }^{37}$

Ivo Renato D’Ávila França ${ }^{38}$ estuda a intertextualidade entre a obra literária e a minissérie, uma vez que a primeira é produto da utilização da palavra escrita e a segunda, resultado de imagens e sons. Para tanto, o autor lança mão de um duplo olhar sobre a narrativa e sua adaptação para a televisão, tendo como objeto de análise o texto original, de Rachel de Queiroz, o roteiro de adaptações de Jorge Furtado e Carlos Gerbase, e a produção televisual da Rede Globo de Televisão, sendo o foco a performance da protagonista Maria Moura. Sua leitura aborda, primeiramente, o processo de adaptação do romance ao roteiro, seguindo o recorte da construção da personagem no romance e na minissérie. Além disso, o autor usa como complemento a contextualização do romance em relação aos demais textos ficcionais da escritora, à historiografia e à crítica literária brasileira. Considera, ainda, que a designação “adaptação” justifica a transposição do romance à minissérie, ainda que estabeleça ora aproximações, ora distanciamentos entre as duas obras.

${ }^{36}$ FIGUEIREDO. Regionalismo na TV: o sertão e o jagunço, uma travessia da literatura para a televisão - um estudo sobre o conceito e a imagem do sertão e do jagunço na TV brasileira a partir das adaptações literárias: Grande sertão: veredas e Memorial de Maria Moura.

${ }^{37}$ FIGUEIREDO. Regionalismo na TV: o sertão e o jagunço, uma travessia da literatura para a televisão - um estudo sobre o conceito e a imagem do sertão e do jagunço na TV brasileira a partir das adaptações literárias: Grande sertão: veredas e Memorial de Maria Moura, p. 35.

${ }^{38}$ FRANÇA. Memorial de Maria Moura em dupla poética de olhar: do romance de Rachel de Queiroz à minissérie de televisão. 


\section{A FORTUNA CRÍTICA DE RACHEL DE QUEIROZ SEGUNDO LíGIA CHIAPPINI}

A obra Literatura e cultura no Brasil: identidades e fronteiras, de Lígia Chiappini, contém um longo artigo, ${ }^{39}$ que é um dos textos críticos de suma importância para quem pretende pesquisar as trilhas literárias de Rachel de Queiroz. Nele, a autora apresenta um verdadeiro "inventário" de questões sobre a ficção queiroziana, incluindo o último romance. Para tanto, Chiappini utiliza-se de uma bibliografia crítica que "vai de Adonias Filho a José Hildebrando Dacanal, passando por Antonio Candido, José Aderaldo Castelo, Alfredo Bosi, Fábio Lucas, Zenir Campos Reis e Flora Süssekind, estudiosos que se debruçaram sobre o chamado romance de 30”, fazendo-os dialogar com pesquisadores de outras áreas que também se interessaram pelo romance de 30: "entre esses estão o sociólogo Sérgio Miceli, (...) a historiadora Rosa Maria Godoy Silveira e o historiador Durval Muniz de Albuquerque.”40

Segundo Chiappini, Durval Muniz de Albuquerque em A invenção do Nordeste trata de forma mais direta de Rachel de Queiroz como integrante de um grupo que se interessa pela construção de um futuro sem resquícios e de um passado elitista, trabalhando o regional como referência para o nacional:

Para autores como Rachel de Queiroz e José Américo, o sertão aparece como o repositório do verdadeiro caráter nacional, reduto de uma sociabilidade comunitária, familiar e orgânica, onde os valores e os modos de vida contrastam com a civilização capitalista moderna, com a ética burguesa assentada no individualismo, no conflito e na mercantilização de todas as relações. (...) O tema da dissolução, da decadência, seja física, seja moral, dos personagens, submetidos a essas novas relações sociais, (...) é constante, seja em José Lins, mais voltado para abordar a sociedade açucareira, (...) seja em Rachel de Queiroz e José Américo, que tomam o sertão como último reduto desta sociabilidade após a decadência da sociedade canavieira. ${ }^{41}$

Entretanto, concorda com alguns críticos que veem a busca do homem "natural”, propósito do estilo racheliano, como forma de representação do sertanejo que busca sempre o retorno ao sertão. É certo que Guta (As três Marias), Dôra (Dôra, Doralina) e Maria Moura (Memorial de Maria Moura) retornem e retomem suas vidas prosseguindo por meio de um fio do passado, mas essas atitudes não são ideais; são, antes de tudo, reais. Talvez esse seja um dos pontos que justifiquem a literatura de Rachel como neorrealista.

\footnotetext{
${ }^{39}$ CHIAPPINI. Rachel de Queiroz: invenção do Nordeste e muito mais, p. 157-176.

${ }^{40}$ CHIAPPINI. Rachel de Queiroz: invenção do Nordeste e muito mais, p. 157.

${ }^{41}$ Albuquerque, 2009, citado por CHIAPPINI. Rachel de Queiroz: invenção do Nordeste e muito mais, p. 163-164.
} 
Na terceira parte de seu artigo, Lígia Chiappini apresenta um contraponto à leitura de Albuquerque, que ela chama de "desatenta e, no mínimo assexuada, para não dizer machista”. ${ }^{42}$ Sua proposta agora é apresentar a leitura dos textos de Rachel feita por mulheres. Inicia por aprofundar-se no artigo de Mônica Raissa Schpun. ${ }^{43}$. A questão escolhida foi aquela que diz respeito às escolhas amorosas de Maria Moura, o seu confronto entre a entrega à submissão e a defesa da terra, que é, para ela e seu meio, símbolo de poder, "num tempo e lugar em que se gestava a tradição da grilagem em vigor até hoje no Brasil”. ${ }^{44}$ A leitura dos textos de Rachel traz a desconstrução dos mitos, não dando espaços, portanto, para a idealização. Isso é bem trabalhado no texto em todas as esferas da obra de Rachel desde as peças teatrais, como a que explora o cangaço ${ }^{45}$ até os romances, especialmente Memorial de Maria Moura, que resgata a tradição cangaceira do interior nordestino.

Nicole Guenot Baranes ${ }^{46}$ traz, segundo Lígia, um estudo sistemático das figuras femininas de cinco romances da autora, excluindo apenas $O$ galo de ouro. Apesar de considerar o trabalho ingênuo e linear, Chiappini afirma que ele é pioneiro e importante, por conter conclusões preciosas sobre as personagens queirozianas. Um dos aspectos instigantes relaciona-se às páginas que vão aumentando de romance para romance, indicando, possivelmente, um alargamento da imaginação que provoca um volume extra na obra da autora. ${ }^{47} \mathrm{E}$, ao passo que vão alcançando esse volume, vai-se utilizando o flashback, “os saltos no tempo, os movimentos recorrentes, as estruturas circulares" ${ }^{\text {48 }}$ e, progressivamente, carregando de complexidade as protagonistas. Exceção feita à Maria Moura, todas as outras personagens fazem o movimento de ir e vir do sertão para a cidade, mas sempre fincado o pé no sertão, o que lembra o próprio movimento da autora, que sempre migrava para a cidade, mas refugiava-se, como que para recarregar sua força, em sua fazenda, que tinha, simbolicamente, o nome "Não me deixes".

\footnotetext{
${ }^{42}$ CHIAPPINI. Rachel de Queiroz: invenção do Nordeste e muito mais, p. 167.

${ }^{43}$ SCHPUN. Mônica Raissa. Lé com lé, cré com cré? Fronteiras móveis e imutáveis em Memorial de Maria Moura.

${ }^{44}$ CHIAPPINI. Rachel de Queiroz: invenção do Nordeste e muito mais, p. 167.

${ }^{45}$ QUEIROZ. Lampião.

${ }^{46}$ BARANES. Presence de la femme dans l'œuvre romanesque de Rachel de Queiroz.

${ }^{47}$ É interessante pensar o conjunto de romances por esse aspecto. O quinze contém 142 páginas (77. ed.); João Miguel, 117 p. (7. ed.); Caminho de pedras, 150 p. (11. ed.); As três Marias, 111 p. (v. 2); Dôra, Doralina, 270 p. (v. 2); Memorial de Maria Moura, 482 p. (9. ed.).

${ }^{48}$ CHIAPPINI. Rachel de Queiroz: invenção do Nordeste e muito mais, p. 169.
} 
Seguindo a trilha da crítica feminina aos textos de Rachel, Ligia Chiappini analisa a dissertação de mestrado de Heloísa Gomes Saraiva. ${ }^{49}$ A pesquisa detém-se nos romances, exceto os dois últimos, O galo de ouro e Memorial de Maria Moura, e em algumas crônicas da primeira coletânea. ${ }^{50}$ A autora as identifica "como matriz de cenas e passagens dos romances”, especialmente de Dôra, Doralina. Para ela, a crônica "Retrato de um brasileiro" seria o embrião do folhetim $O$ galo de ouro.

Para finalizar seu artigo, Ligia Chiappini destaca os textos de Vilma Arêas, Heloísa Buarque de Hollanda e Vera Borges. A segunda autora, no já citado artigo “O éthos Rachel”, destaca, entre outras questões, o papel das matriarcas cearenses como inspiradoras para a escrita da autora. Não há como referir-se às matriarcas nordestinas sem mencionar aquelas da família de Rachel. D. Bárbara, a célebre avó de José de Alencar e quinta avó de Rachel de Queiroz, teria lutado na Confederação do Equador, enviuvando-se aos 45 anos e tendo que administrar sozinha a fazenda que herdara, assim como Senhora e, posteriormente, Dôra, em Dôra, Doralina. No artigo "Rachel: o ouro e a prata da casa”, de Vilma Arêas, Chiappini vê a descrição de Conceição em $O$ quinze como “alegoria da seca”, mas visualiza a intenção de Rachel na desconstrução dos mitos, preconceitos e expectativas. ${ }^{51} \mathrm{O}$ artigo trata da memória nos textos queirozianos e menciona a inter-relação entre as crônicas da primeira coletânea - $A$ donzela e a moura torta (1948) - e os romances Dôra, Doralina e Memorial de Maria Moura.

Lígia Chiappini encerra citando “A representação do feminino em Rachel de Queiroz e Jorge Amado”, em que Vera Borges compara as protagonistas de Rachel (das obras O quinze, Dôra, Doralina e Memorial de Maria Moura) às de Jorge Amado (das obras Gabriela, cravo e canela, Dona Flor e seus dois maridos e Tereza Batista cansada de guerra). Vera Borges atenta para o fato de que Rachel prioriza a descrição do pensamento e das ações de suas personagens, trabalhando com mulheres representantes de todas as camadas sociais, que têm em comum a orfandade e a ausência de continuidade, uma vez que nenhuma deixa filhos. ${ }^{52} \mathrm{O}$ gran finale delas é a solidão, preço que pagam pela sua rebeldia.

Em relação às protagonistas de Jorge Amado, Vera Borges realça que elas são descritas privilegiando-se o aspecto físico de mulher mestiça e detentora de uma beleza

\footnotetext{
${ }^{49}$ SARAIVA. As pedras do caminho: a ficção de Rachel de Queiroz e sua trajetória.

${ }^{50}$ QUEIROZ. A donzela e a moura torta.

${ }^{51}$ CHIAPPINI. Rachel de Queiroz: invenção do Nordeste e muito mais, p. 172.

${ }^{52}$ Conceição, em $O$ quinze, adota um afilhado. Isso lhe confere uma atitude ‘avançada’ para a época pelo fato de ser solteira; Maria Moura, em Memorial de Maria Moura, também tem um afilhado a quem deve deixar sua herança, uma vez que não tem filhos, nem irmãos, tanto quanto suas antecessoras.
} 
estonteante. São mulheres pobres que rompem com a tradição porque não trazem lembranças de família, não demonstram amor à terra. As protagonistas de Jorge Amado não têm filhos, assim como as de Rachel, mas, ao contrário destas, sentem o vazio da ausência da maternidade. São submissas ao homem e não competem com eles, preferindo a obediência à solidão. Segundo Lígia Chiappini, Vera Borges acredita que haja nos textos de Rachel uma intenção latente de se construir personagens mais complexas, mas que a representação feminina na obra ainda é dominada pelo masculino, uma vez que, para creditarem poder a si, essas mulheres precisam agir como homens. É bem isso o que Maria Moura faz, e a prova cabal é o corte dos cabelos e as roupas de homem (do pai), simbolizando o resgate da tradição.

\title{
CONSIDERAÇÕES FINAIS
}

O levantamento crítico aqui exposto foi feito para evidenciar a importância de Rachel de Queiroz para a literatura e a crítica brasileiras e também para confirmar a viabilidade dos textos da autora em variados níveis de conhecimento e sob diversas óticas. Constatou-se que as várias críticas levantadas incidiram, principalmente, sobre o último romance de Rachel de Queiroz. No âmbito acadêmico, abarcaram diferentes tendências, como estudos intersemióticos - pela adaptação para a televisão -, crítica genética, especialmente do romance Memorial de Maria Moura, sendo boa parte dessa pesquisa advinda da Universidade Federal Fluminense.

Vários estudos críticos destacaram a questão do regionalismo na obra de Rachel de Queiroz, o que não surpreende, uma vez que foi com a temática regionalista que Rachel se inseriu no mundo das letras, valendo-se das palavras para conquistar o seu espaço e, por isso, incomodou. Alterou o cânone literário, visto que trouxe a escrita feminina para o centro das discussões e manteve, a partir da publicação de $O$ quinze, um novo fazer literário crítico de seu tempo e espaço, interpretando de maneira sensível a realidade brasileira.

\begin{abstract}
This essay intends to present, a part time, the available critique about Rachel de Queiroz since first novel, O quinze (1930), until Memorial de Maria Moura (1992), emphasized the critique about the last novel of more strong.
\end{abstract}




\section{KEYWORDS}

Rachel de Queiroz, Brasilian literary, Novel Critique

\section{REFERÊNCIAS}

ANDRADE, Mário. O empalhador de passarinho. 3. ed. São Paulo: Livraria Martins, 1972.

ARÊAS, Vilma. Rachel: o ouro e a prata da casa. In: INSTITUTO MOREIRA SALLES. Cadernos de Literatura Brasileira: Rachel de Queiroz. São Paulo, v. 4, set. 1997, p. 87-102.

ARRIGUCCI JÚNIOR, Davi. O sertão em surdina. In: segredos. Rio de Janeiro: Companhia das letras, 2010. p. 87-99.

(Org.). O guardador de

BARBOSA, Lúcia Dias Leite. Protagonistas de Rachel de Queiroz: caminhos e descaminhos. São Paulo: Pontes, 1999.

BORNHEIM, Gerd (Org.). Tradição contradição. Rio de Janeiro: Jorge Zahar: Funarte, 1987.

CANDIDO, Antonio. A vida ao rés-do-chão. In: . (Org.). A crônica: o gênero, sua fixação e suas transformações no Brasil. Campinas: Editora Unicamp, 1992; Rio de Janeiro: Fundação Casa de Rui Barbosa, 1992. p. 13-22.

CARVALHO, Francisco. Textos e contextos. Fortaleza: Universidade Federal do Ceará; Casa de José de Alencar, 1995.

CHIAPPINI, Lígia. Literatura e cultura no Brasil: identidades e fronteiras. São Paulo: Cortez, 2002.

CHIAPPINI, Lígia. Rachel de Queiroz: invenção do Nordeste e muito mais. In:

Literatura e cultura no Brasil: identidades e fronteiras. São Paulo: Perspectiva, 2002. p. 157176.

COELHO, Nelly Novaes. Dicionário crítico de escritoras brasileiras. São Paulo: Escrituras, 2002.

COSTA, Maria Osana de Medeiros. Maria Moura, uma saga de poder, amor e morte. In: DUARTE, Constância Lima; DUARTE, Eduardo Assis; BEZERRA, Kátia da Costa (Org.). Gênero e representação na literatura brasileira. Belo Horizonte: Pós-Graduação em Letras: Estudos Literários, Faculdade de Letras/UFMG, 2002. v. 2. p. 183-189.

DUARTE, Eduardo de Assis. Classe e gênero no romance de Rachel de Queiroz. In: Literatura, política, identidades. Belo Horizonte: Fale/UFMG, 2005. p. 105-112.

FIGUEIREDO, Ana M. Camargo. Regionalismo na TV: o sertão e o jagunço, uma travessia da literatura para a televisão - um estudo sobre o conceito e a imagem do sertão e do jagunço na TV brasileira a partir das adaptações literárias: Grande sertão: veredas e Memorial de Maria Moura. 2008. 182 f. Dissertação (Mestrado) - Faculdade de Letras, Universidade de São Paulo, São Paulo, 2008.

FILHO, Adonias. O romance brasileiro de 30. Rio de Janeiro: Bloch, 1969.

FRANÇA, Ivo Renato D’Ávila. Memorial de Maria Moura em dupla poética de olhar: do romance de Rachel de Queiroz à minissérie de televisão. 2005. 196 f. Dissertação (Mestrado) - Universidade Federal de Santa Catarina (UFSC), Florianópolis, 2005. 
HOLLANDA, Heloísa Buarque. O éthos Rachel. In: INSTITUTO MOREIRA SALLES. Cadernos de Literatura Brasileira: Rachel de Queiroz. São Paulo, v. 4, p. 103-115, set. 1997.

HOUAISS, Antônio. Memorial de Maria Moura. Jornal do Comércio, Rio de Janeiro, p. 4-6. 6 out. 1992.

INSTITUTO MOREIRA SALLES. Cadernos de literatura brasileira: Rachel de Queiroz. São Paulo, v. 4, set. 1997.

LANGARO, Jerri Antonio. De Sinhazinha a Jagunça / de Senhorinha a Senhora: uma leitura de Memorial de Maria Moura e Dôra, Doralina. 2006. 181 f. Dissertação (Mestrado em Educação, Comunicação e Artes) - Universidade Estadual do Oeste do Paraná, Cascavel, 2006.

LANS, Lausimar. A fenomenologia da comunicação em Rachel de Queiroz. Minas Gerais, Belo Horizonte, jan. 1975. Suplemento Literário, p. 11-16.

MARTINS, Wilson. Rachel de Queiroz em perspectiva. In: INSTITUTO MOREIRA SALLES. Cadernos de Literatura Brasileira: Rachel de Queiroz. São Paulo, v. 4, set. 1997, p. 69-86.

PACHECO, Antônio Carlos de Miranda. Personagens em construção no Memorial de Maria Moura: estudo da gênese do Beato Romano. 2007. 128 f. tese (Doutorado) - Centro de Estudos Gerais, Instituto de Letras, Universidade Federal Fluminense, Niterói, 2007.

PERPÉTUA, Elzira Divina. [Rachel de Queiroz]. Disponível em: <http://www.abralic.org.br/htm/congressos/anis-eventos.htm>. Acesso em: 12 dez. 2008.

QUEIROZ, Rachel. Lampião. Rio de Janeiro: José Olympio, 1953.

QUEIROZ, Rachel. Rachel de Queiroz. Jornal do Brasil, Rio de Janeiro, 14 mar. 1970. Entrevista concedida a Ary Quintella.

QUEIROZ, Rachel. João Miguel. 7. ed. Rio de Janeiro: José Olympio, 1978.

QUEIROZ, Rachel. As três Marias. Rio de Janeiro: José Olympio, 1989. (Obra reunida; v. 2)

QUEIROZ, Rachel. Dôra, Doralina. Rio de Janeiro: José Olympio, 1989. (Obra reunida; v. 2)

QUEIROZ, Rachel. A donzela e a moura torta. Rio de Janeiro, 1989. (Obra reunida; v. 3)

QUEIROZ, Rachel. Caminho de pedras. 11. ed. São Paulo: Parma, 1990.

QUEIROZ, Rachel. As três Rachéis (Entrevista). In: INSTITUTO MOREIRA SALLES. Cadernos de literatura brasileira: Rachel de Queiroz. São Paulo, n. 4, set. 1997.

QUEIROZ, Rachel. Memorial de Maria Moura. 9. ed. Rio de Janeiro: Siciliano, 1998.

QUEIROZ, Rachel. O Quinze. 77. ed. Rio de Janeiro: José Olympio, 2004.

RAMOS, Graciliano. Linhas tortas. 8. ed. São Paulo: Record, 1980.

SARAIVA, Heloísa Gomes. As pedras do caminho: a ficção de Rachel de Queiroz e sua trajetória. 1992. 122 f. Dissertação (Mestrado) - Faculdade de Letras, Universidade Federal do Rio de Janeiro, Rio de Janeiro, 1992.

SCHPUN, Mônica Raissa. Lé com lé, cré com cré? Fronteiras móveis e imutáveis em Memorial de Maria Moura. In: CHIAPPINI, Lígia. Literatura e cultura no Brasil: identidades e fronteiras. São Paulo: Cortez, 2002. p. 177-186.

TAMARU, Ângela Harumi. A construção literária da mulher nordestina em Rachel Queiroz. 2004. 188 f. Tese (Doutorado) - Universidade Estadual de Campinas, Campinas, 2004. 
VILALVA, Walnice Aparecida Matos. Marias: estudo sobre a donzela-guerreira no romance brasileiro. 2007. 193 f. Tese (Doutorado) - Universidade de Campinas, Campinas, 2004. 